\title{
Reflexões sobre o direito à educação da pessoa com deficiência
}

\section{Reflections on the education right of disabled persons}

Reflexiciones acerca del derecho a la educación de la persona con discapacidad

\author{
Michel Canuto de Sena ${ }^{1}$ \\ Paulo Roberto Haidamus de Oliveira Bastos ${ }^{2}$ \\ Heitor Romero Marques ${ }^{3}$ \\ Graciele Silva ${ }^{4}$
}

${ }^{1}$ Doutorando e mestre pelo Programa de Pós-Graduação em Saúde e Desenvolvimento na Região Centro-Oeste, da Universidade Federal de Mato Grosso do Sul (UFMS). Especialista em Direito Civil e Direito Processual Civil. Graduado em Direito. Professor de Direito Civil na UFMS. E-mail: canuto.fadir.ufms@gmail.com

${ }^{2}$ Doutor e mestre em Educação (Currículo) pela Pontifícia Universidade Católica de São Paulo (PUC-SP). Graduado em Farmácia Bioquímica pela Universidade Federal de Mato Grosso do Sul (UFMS). Professor

Titular Aposentado da UFMS. Professor Permanente, Pesquisador Sênior do Programa de Pós-Graduação Stricto Sensu em Saúde e Desenvolvimento na Região Centro-Oeste (PPGSD) (Mestrado e Doutorado). E-mail: phaidamus43@gmail.com

${ }^{3}$ Doutor em Desarrollo Local Y Planteamiento Territorial pela Universidad Complutense de Madrid. Mestre em Educação Formação de Professores pela Universidade Católica Dom Bosco (UCDB). Especialista em Filosofia e História

da Educação, Graduado em Ciências e em Pedagogia pelas Faculdades Unidas Católicas de Mato Grosso (FUCMT). Graduado em Educação Moral

e Cívica Exame de Suficiência e em Ciências de Primeiro Grau Exame de Suficiência pela Universidade Federal de Goiás (UFG). Professor na

Universidade Católica Dom Bosco. E-mail: heiroma@ucdb.br

${ }^{4}$ Especialista em Direito Civil e Direito Processual Civil e graduada em Direito pela Universidade Católica Dom Bosco (UCDB).

E-mail: gracieleesilva@yahoo.com 
Resumo: A pessoa com deficiência possui o direito de ser integrada na sociedade e em diversos meios sociais decorrentes de uma educação inclusiva. O presente artigo propõe reflexão sobre o direito à educação e inclusão da pessoa com deficiência. Trata-se de revisão teórica baseada em livros, teses e dissertações, decretos e leis, relacionados à pessoa com deficiência. Serão abordadas questões conceituais, aspectos históricos, sociais, éticos e o direito dessas pessoas como determina o ordenamento jurídico vigente (Constituição Federal, Código Civil e leis especiais), políticas públicas de inclusão no ambiente escolar, as dificuldades e as garantias em caso de descumprimento e/ou desrespeito desses direitos. Porém se faz necessário um olhar crítico e reflexivo de como é proporcionada essa inclusão com a participação de toda a sociedade nesse processo.

Palavras-chave: deficiência física; políticas públicas; leis de inclusão; acesso à educação.

\begin{abstract}
Disabled persons have the right to be integrated into society and also in social environments achieved by an inclusive education. This article proposes a reflection on the right to education and the social inclusion of persons with disabilities. Our method was based on a theoretical revision, based on books, theses and dissertations, decrees and laws that were related to the person with a disability. Conceptual issues, historical, social, ethical aspects, and the rights of these persons are determined by the current legal system (Federal Constitution, Civil Code and special laws) and includes major directions such as public policies of inclusion in the school environment and guarantees in case of non-compliance and / or disrespect of these rights. However, it is still necessary to critically and reflectively address at how this inclusion is provided, with the cooperation of all society in this process.
\end{abstract}

Keywords: physical disability; public policy; inclusion laws; access to education.

Resumen: La persona con discapacidad posee derecho de ser integrada en la sociedad y en diversos medios sociales consecuentes de una educación inclusiva .El presente estudio propone una reflexión acerca del derecho a la educación e inclusión de la persona con discapacidad. Se trata de una revisión teórica basada en libros, tesis y disertaciones, decretos y leyes relacionados a la persona con discapacidad. Serán tratados cuestiones conceptuales, aspectos históricos, sociales, éticos y el derecho de las personas como determina el ordenamiento jurídico vigente (Constitución Federal, Código Civil y leyes especiales), políticas públicas de inclusión en el ambiente escolar, las dificultades y garantías en el caso de incumplimiento y/o desrespeto de los derechos. Sim embargo, se hace necesario una mirada crítica y reflexiva de cómo es proporcionado esa inclusión con la participación de toda la sociedad en ese proceso.

Palabras clave: discapacidad física; políticas públicas; leyes de inclusión; acceso a la educación. 


\section{INTRODUÇÃO}

A educação tem função de instruir e formar as pessoas de forma acessível, universal e gratuita, exercendo assim sua função social de levar o conhecimento sem qualquer tipo de preconceito e discriminação para todas as pessoas. Por outro lado, quando é tratada no campo inclusivo de pessoas que possuam algum tipo de limitação permanente ou transitória, surgem as dificuldades. Assim, far-se-á necessário estipular meios e ações que facilitem o reingresso e convivência desse grupo social. Nesse diapasão, a temática do presente trabalho reside na educação e na inclusão da pessoa com deficiência.

Nesse aspecto, a relação da sociedade com pessoas portadoras de deficiência têm passado por transformações no decorrer do tempo; para a inclusão dessas pessoas, o Estado passou a criar meios, visando atender as necessidades específicas de cada um. No Brasil, a proteção constitucional dessas pessoas ocorreu a partir da ratificação da Convenção Internacional da Organização das Nações Unidas (ONU) sobre direitos da pessoa com Deficiência, trabalhando a possibilidade de igualdade para todos.

O problema da pesquisa concentra-se nas escolas, pois grande parte não dispõe de equipe qualificada e de equipamentos necessários para aplicar métodos de ensino diferenciados, a exemplo das pessoas surdas que precisam de intérprete com habilidade em libras para transmitir o conteúdo, levando em consideração também as pessoas que necessitam de transporte adequado, rampas de acessibilidade para cadeirantes, acompanhamento médico, profissional da fisioterapia entre outros recursos. As concepções das práticas institucionalizadas necessitam de reformulações com a intenção de administrar as diferenças na convivência dentro do ambiente escolar.

A presente pesquisa utilizou revisão bibliográfica, buscando estudos e pesquisas sobre a inclusão da pessoa com deficiência física no âmbito escolar, direitos resguardados e políticas públicas associadas à interação dessa pessoa. As referências apresentadas pela literatura sobre o direito à educação da pessoa com deficiência, foram coletadas a partir das bases de dados Medline, SciELO e Lilacs. Utilizando como principais autores Vygotsky (1979), Hofling (2001), Schewinsky (2004) e Carvalho (2016). 
Desse modo, o objetivo do estudo é realizar reflexão acerca dos direito à educação da pessoa com deficiência.

Frente ao exposto, a presente pesquisa tem como justificativa as hipóteses jurídicas e sociais sobre o direito inclusivo, ilustrando as vertentes pessoais, sociais e escolares das pessoas com deficiência.

\section{REVISÃO DE LITERATURA}

\subsection{Deficiência física: aspectos teóricos e conceituais}

O sistema nervoso é responsável pelas funções do corpo e pelas tarefas sensoriais, como sentir odores, falar e produzir lembranças, controlando os movimentos corporais e regulando o funcionamento dos órgãos. Essas funções se dividem em função sensitiva, responsável pelos estímulos internos e externos; função integradora, que compõe o sistema nervoso, responsável por processar, analisar e armazenar parte da informação sensitiva, tomando decisões para as respostas apropriadas; e função motora, que, uma vez integrada à função sensitiva, fica responsável por promover resposta motora adequada (TORTORA; DERRICKSON, 2012).

A deficiência física pode ser definida como perda ou anormalidade de estrutura, função psicológica, fisiológica ou anatômica, podendo ser permanente ou temporária, inserindo nesse contexto a anomalia, defeito ou perda de membros, órgãos, tecidos ou qualquer outra estrutura do corpo, incluindo funções mentais, possivelmente gerando incapacidade nas habilidades desenvolvidas pelo ser humano (AMIRALIAN et al., 2000).

A sociedade, por muito tempo, estabeleceu tratamentos cruéis e preconceituosos às pessoas portadoras de deficiência. No Egito antigo, a sociedade considerava que os maus espíritos eram os provocadores da deficiência física; assim, os mais pobres eram estigmatizados sem os devidos tratamentos enquanto os mais ricos tinham tratamentos adequados. Para os hebreus seguidores da lei de Moisés, as pessoas com deficiências físicas não poderiam fazer oferendas a Deus, pois os deficientes eram vistos como impuros (SCHEWINSKY, 2004).

Na Grécia, os indivíduos com estrutura corporal forte eram valorizados e escalados como guerreiros, em contrapartida os deficientes eram 
marginalizados ou até eliminados, porém o Estado protegia os guerreiros mutilados em batalhas. Os romanos enalteciam o corpo perfeito, e os deficientes eram vistos como monstros, condenando à morte os bebês com malformação (ROSSETTO et al., 2006).

Com o surgimento do Cristianismo, a sociedade passou a ser mais humanizada, partindo do pressuposto de que todos os indivíduos são seres criados por Deus, acreditando que as deformidades não condenavam a alma. Em decorrência dessa linha de pensamento, o Imperador Constantino criou uma lei em 315 depois de Cristo, protegendo as pessoas com deficiência, porém, no período bizantino, essa regra não foi seguida pela Igreja Católica, aplicando possíveis punições aos deficientes que eram levados para mosteiros (ROSSETTO et al., 2006).

No século XVI, o tratamento às pessoas deficientes foi legitimado pelos médicos alquimistas, que estabeleceram diferenças e conceitos de deficiência, distinguindo a visão moral da cientifica. Nos séculos subsequentes, a medicina passou a ser social e humanista, incrementando a assistência aos deficientes (ROSSETTO et al., 2006).

Mais adiante, no século XX, após o fim da guerra e com a revolução industrial, foram criados programas de reabilitação para pessoas acidentadas e mutiladas, na tentativa de inserir o deficiente no meio social (SCHEWINSKY, 2004).

Nesse aspecto, dados da Organização Mundial de Saúde (OMS), demonstram que cerca de $10 \%$ da população possuem algum tipo de deficiência, essas pessoas passam por barreiras que possivelmente impeçam-lhe a participação efetiva em sociedade (BRASIL, 2011).

Segundo dados do IBGE (BRASIL, 2012a), 23,9\% da população residente no país possui algum tipo de deficiência, podendo ser visual, auditiva, motora, mental ou intelectual, variando da seguinte forma:

A prevalência da deficiência variou de acordo com a natureza delas. A deficiência visual apresentou a maior ocorrência, afetando 18,6\% da população brasileira. Em segundo lugar está a deficiência motora, ocorrendo em $7 \%$ da população, seguida da deficiência auditiva, em $5,10 \%$ e da deficiência mental ou intelectual, em 1,40\%. [...] Os dados do censo mostraram que a deficiência atinge as pessoas em qualquer idade, algumas pessoas nascem com ela, outras a adquirem ao longo 
da vida. O contingente populacional que tem pelo menos uma das deficiências investigadas pelo Censo de 2010 revela que sua prevalência é bastante alta na população brasileira e se distribui por todos os grupos de idade. No entanto, podemos observar um forte aumento nos grupos de idade de 5 a 9 anos e de 40 a 44 anos. A partir desse último grupo, a prevalência da deficiência cresceu acentuadamente. $\mathrm{Na}$ faixa de 40 a 59 anos, ocorreu o maior contingente de pessoas com deficiência, cerca de 17,4 milhões de pessoas, dos quais 7,5 milhões eram homens e 9,9 milhões eram mulheres. (BRASIL, 2012a, p. 6-8).

Em síntese, a pessoa com deficiência sofre limitações, deparando-se com ausência de políticas públicas adequadas, devido à falta de planejamento governamental com atenção baseada nas necessidades especiais.

\subsection{Políticas públicas de inclusão}

Quando o assunto trata de pessoas com deficiência, dá-se o direcionamento para as políticas públicas e também para os direitos humanos, buscando a garantia de vida digna, sem tratamentos discriminatórios. Tais indivíduos possuem dificuldade de ouvir, enxergar, locomoção, ou até mesmo deficiência mental. A Constituição Federal de 1988 estabelece a competência comum da União, dos Estados, do Distrito Federal e dos municípios de cuidar da saúde e demais assistência das pessoas com deficiência.

As políticas públicas podem ser definidas como ações governamentais voltadas para determinados grupos ou setores na sociedade, decorrentes da responsabilidade do Estado, para implantar e manter tais programas em parceria com outros órgãos públicos e agentes da sociedade, buscando diminuir as desigualdades estruturais existentes (HÖFLING, 2001).

Desse modo, as políticas públicas é um processo de longo e médio prazo, que deve identificar e adequar o problema social com a respectiva política, que se completa com a formação de uma agenda pública, implica processo para política de tomada de decisão e implementação da política pública e execução dessas políticas com acompanhamento, monitoramento e avaliação para decidir sobre a continuidade, reestruturação ou extinção desse processo (BENEDITO; MENEZES, 2013).

A política de atenção às pessoas com deficiência (PD) preconiza um conjunto de ações destinadas a atender às necessidades dessa 
população no referente à saúde, educação, trabalho, relacionamento afetivo e social. No Brasil, o movimento das pessoas com deficiência, amparado pela Coordenação Nacional para a Integração da Pessoa Portadora de Deficiência (CORDE), vem conseguindo desmistificar crenças e valores acerca do que é ser pessoa com deficiência, sobretudo ao obter a sanção, pelo Estado, de legislação específica que assegure a inclusão social dessas pessoas. (FRANÇA; PAGLIUCA, 2008, p. 130).

As políticas públicas destinadas para as pessoas que necessitam de atendimentos especiais permitem o acesso a bens e serviços, que auxiliam na acessibilidade e equiparam as oportunidades para as pessoas portadoras de deficiência, fazendo cumprir os direitos fundamentais já estabelecidos (BRASIL, 2012b).

Por conseguinte a Organização das Nações Unidas (ONU) considera pessoas deficientes como cidadãs possuidoras de direitos e obrigações, que participam contribuindo para o crescimento social. Para tanto são utilizados os seguintes aspectos: (I) ter a dignidade da pessoa humana reconhecida, ter uma vida decente e plena o quanto possível; (II) isonomia em direitos civis e políticos; (III) direito a tratamento médico, funcional, psicológico e acesso a aparelhos, reabilitação médica, educação e demais assistências médicas assistidas; (IV) ter acesso ao direito social e econômico, por meio de desenvolvimento de atividades produtivas e com a respectiva remuneração; (V) direito de proteção contra possíveis discriminações e explorações e (VI) Direito das organizações de pessoas deficientes de serem consultadas em todos os assuntos referentes aos direitos de pessoas deficientes (BRUMER; PAVEI; MOCELIN, 2004).

Desse modo, a Convenção Interamericana para a Eliminação de todas as formas de discriminação da pessoa com deficiência reafirma que as pessoas portadoras de deficiência têm os mesmos direitos humanos e liberdades fundamentais que outras pessoas, e que estes direitos, inclusive o direito de não serem submetidas à discriminação com base na deficiência, emanam da dignidade e da igualdade que são inerentes a todo ser humano (BRASIL, 2001a).

No Brasil, a Constituição Federal (BRASIL, 1988) rompeu com o modelo assistencialista e passou a olhar para as necessidades das pessoas 
com deficiência. Em 1990, o Estatuto da Criança e do Adolescente (ECA) estabeleceu que as pessoas portadoras de necessidades especiais gozam de direitos de modo isonômico e não apenas de assistência social. Nesse sentido, esse grupo de pessoas conquistou a própria identidade, espaço e respeito dentro da sociedade, conforme o princípio da igualdade e equidade, que reconhece a necessidade de condições diferenciadas para o portador de deficiência (BRASIL, 2001b).

Nesse contexto, as atribuições do atendimento educacional especializado fortalece o sistema inclusivo, busca maior autonomia e participação dos envolvidos, utilizando-se de recursos e serviços que identificam e proporcionam as habilidades funcionais de cada um levando em consideração a participação dos alunos, pais ou responsáveis (BENEDITO; MENEZES, 2013).

Desse modo, as políticas de inclusão social e o acesso à educação são garantias constitucionais, cabendo ao Estado promover ações para implementação dessas políticas decorrente de uma relação jurídica administrativa.

\subsection{Direito à educação da pessoa com deficiência}

Em 1960, o movimento da integralização social se fortaleceu em prol dos direitos humanos e da evolução científica. No Brasil, esse movimento passou a ser discutido na década de 1970, tratado como matéria especial nos moldes da integralização escolar até o início da década de 1990; desde então; o discurso foi ampliado, tornando-se acessível à educação inclusiva.

Nessa linha de entendimento, Vygotsky defendia que a criança portadora de deficiência seria capaz de desenvolver-se com o convívio social e cultural, e os estímulos recebidos seriam capazes de compensar a deficiência como uma superação, assim,

[...] um defeito ou problema físico, qualquer que seja sua natureza, desafia o organismo. Assim, o resultado de um defeito é invariavelmente duplo e contraditório. Por um lado, ele enfraquece o organismo, mina suas atividades e age como uma força negativa. Por outro lado, precisamente porque torna a atividade do organismo difícil, o defeito age como um incentivo para aumentar o desenvolvimento de outras funções no organismo; ele ativa, desperta o organismo para redobrar atividade, que compensará o defeito e superará a dificuldade. Esta 
é uma lei geral, igualmente aplicável à biologia e à psicologia de um organismo: o caráter negativo de um defeito age como um estímulo para o aumento do desenvolvimento e da atividade. (COSTA, 2006, p. 233).

Nesse contexto, as formas de ensino ministradas em salas de aula, possuíam formato pouco didático e escassez de recursos aplicáveis para educação inclusiva de crianças especiais; a não inclusão dessas crianças nas escolas, significava a falta de profissionais especializados (FRANÇA; PAGLIUCA; BAPTISTA, 2008).

O direito das pessoas com deficiência à educação e inclusão social está garantido na Constituição Federal de 1988 e em leis especiais (SENA et al., 2017). Por outro lado, quando os conceitos legais são aplicados na prática, os possíveis obstáculos dificultam a concretização da proposta de inclusão no ensino. Assim, as leis de diretrizes e bases da educação facilitam a reflexão contributiva com foco na inclusão social (CARVALHO; SALERNO; ARAUJO, 2015).

O Brasil comprometeu-se a eliminar todas as formas de discriminação, contra as pessoas portadoras de deficiência, possibilitando e instituindo os mesmos direitos humanos e liberdades fundamentais que as demais pessoas, sendo este o de não submeter a nenhum tipo de discriminação com base em sua deficiência, pois o princípio da dignidade da pessoa humana abrange todo ser humano (BRASIL, 2001a).

[...] as pessoas com deficiência carecem de políticas estruturais que propiciem geração permanente de renda. O problema deste tipo de iniciativa é a lentidão para que seus benefícios sejam sentidos, como atestam as políticas educacionais tradicionais - surtem efeito apenas quando o indivíduo começa a trabalhar. [...] o problema da política social brasileira em geral, e aquela voltada às pessoas com deficiência, em particular, é a dominância do aspecto compensatório continuado que não deixa raiz na vida das pessoas. Isto porque uma vez interrompido o programa a sua clientela volta à marginalidade original. (NERI et al., 2003, p. 70).

A educação inclusiva parte do pressuposto que a escola deve fazer parte da vida de todos, atendendo as necessidades de cada indivíduo, para efetivar a inclusão social e educacional, sendo necessárias transformações 
políticas, curriculares, estruturais, ideológicas e de formação e capacitação de profissionais (ARAUJO; MAIA, 2016).

A inclusão da pessoa portadora de deficiência sob a ótica constitucional institui alguns princípios basilares, dentre eles a dignidade da pessoa humana e a igualdade de todos. Nesse sentido, o princípio da isonomia deve ser entendido como justiça distributiva, tratando igualmente os iguais e desigualmente os desiguais, na medida de suas desigualdades (ARAUJO; MAIA, 2016).

Em que pese à Educação Inclusiva, esta garante a escola como um espaço de todos, no qual os alunos possam buscar o conhecimento, sem quaisquer limitações de seu direito em participar ativamente das atividades (CARVALHO; SALERNO; ARAUJO, 2015). A Lei n. 9.394/96 (BRASIL, 1996) dispõe que o serviço na educação deve ser ofertado no ensino regular em classes comuns, considerando que a escola é um ambiente de igualdade e equilíbrio para o desenvolvimento da personalidade do indivíduo (CARVALHO; SALERNO; ARAUJO, 2015).

Nesse sentido, conforme o entendimento de Sousa, Lopes e Maia (2014, p. 109):

A Constituição Federal de 1988, expressa, o direito à inclusão de pessoas com necessidades educacionais especiais ao afirmar, em seus artigos 205 e 206, que a educação é direito de todos os cidadãos brasileiros. A Lei não diferencia as pessoas, ou seja, a educação é para todos, e a escola tem que possibilitar igualdade de condições para o seu acesso, proporcionando situações e quesitos para que a pessoa possa entrar, permanecer e sair com êxito. Na esfera documental, o Estatuto da Criança e do Adolescente - ECA, instituído em julho de 1990, também corrobora com os princípios constitucionais, dentre eles, a educação para todos. Garante ainda às pessoas com deficiências o fornecimento gratuito de medicamentos e próteses pelo poder público.

Segundo o artigo 28 da Lei n. 13.146/15, cabe ao poder público assegurar, criar, desenvolver, implementar, incentivar, acompanhar e avaliar o sistema educacional inclusivo em todos os níveis e modalidades, bem como o aprendizado ao longo de toda a vida (BRASIL, 2015).

Essas políticas públicas passaram a ser prioritárias, proporcionando atendimento especializado com projeto pedagógico direcionado a atender 
às particularidades dos estudantes com deficiência, garantindo iguais condições, adotando medidas individualizadas e coletivas em ambientes que permitam potencializar o desenvolvimento social e educacional (BRASIL, 2015).

O direito à educação é considerado público subjetivo, conforme o $\S$ 10, artigo 208 da Constituição Federal de 1988, essa relação jurídica possui, de um lado, o Estado com o dever jurídico de manter a educação com qualidade para todos, e, de outro, encontra-se o indivíduo com o direito subjetivo de exigir o cumprimento da obrigação educacional por parte do poder público (BIGARELLA; LEWANDOWSKI; CARVALHO, 2017).

Assim, a obrigatoriedade das instituições de ensino privadas de adotarem as medidas estabelecidas no art. 28 do estatuto gerou polêmica, pacificando inclusive jurisprudência sobre o assunto. Conforme entendimento do STF:

[...] É somente no convívio com a diferença e com o seu necessário acolhimento que pode haver a construção de uma sociedade livre, justa e solidária, em que o bem de todos seja promovido sem preconceitos de origem, raça, sexo, cor, idade e quaisquer outras formas de discriminação (Art. 3ํ, I e IV, CRFB). A Lei no 13.146/2015 indica assumir o compromisso ético de acolhimento e pluralidade democrática adotados pela Constituição ao exigir que não apenas as escolas públicas, mas também as particulares, deverão pautar sua atuação educacional a partir de todas as facetas e potencialidades que o direito fundamental à educação possui e que são densificadas em seu Capítulo IV. (BRASIL, 2016).

A Política Nacional de Educação Especial na Perspectiva da Educação Inclusiva prevê que a educação inclusiva constitui um paradigma educacional na concepção de direitos humanos, que conjuga igualdade e diferença como valores indissociáveis e que avança em relação à ideia de equidade formal, ao contextualizar as circunstâncias históricas da produção da exclusão dentro e fora da escola (BRASIL, 2008).

Frente às indagações, o processo de inclusão escolar é responsabilidade de todos, incluindo equipe pedagógica, administrativa, professores e alunos, pois as oportunidades de aprendizagem disponibilizadas pelas unidades de ensino devem ser estendidas a toda a sociedade (RODRIGUEZ; DUTRA; STORTO, 2017 ). 


\section{CONSIDERAÇÕES FINAIS}

Frente ao exposto, a legislação brasileira garante, de forma ampla, o direito das pessoas com deficiência, através de mecanismos que garantem a educação para todas as crianças e adolescentes, independentemente de suas características pessoais.

Desse modo, a luta das pessoas com deficiência conseguiu desmistificar as crenças e valores, que antes as rotulavam com discriminação, passou a ser combatida pelo Estado através de legislação específica, assegurando os direitos e inclusão dessas pessoas.

As políticas de inclusão se utilizam de regras e dos princípios básicos que dignificam o ser humano como pessoa, para orientar e inserir na sociedade as pessoas com deficiência, tendo em vista a necessidade de atendimento digno para superar o preconceito, a vulnerabilidade dentre outros.

Entretanto as situações inclusivas são construídas no dia a dia através das relações interpessoais, sociais e políticas, ficando clara a importância da aceitação dessas pessoas na sociedade, sem quaisquer formas de discriminação por intermédio de políticas públicas de inclusão, que buscam adequar a sua integralização, fundamentando-se nos direitos humanos para garantir vida digna às pessoas com deficiência, sem tratamentos discriminatórios.

As políticas de inclusão social e o acesso à educação são garantias constitucionais, e cabe ao Estado promover ações para implementação dessas políticas, decorrente de uma relação jurídica administrativa.

O direito à educação das pessoas com deficiência está garantido pela Constituição Federal e leis de diretrizes e bases da educação, que buscam inserir uma educação de melhor qualidade, desde a educação básica até a superior, tendo em vista que os alunos com e sem deficiência possam exercer o direito à educação em sua plenitude.

Embora as legislações determinem essa inclusão da pessoa com deficiência, cabe à escola dispor de espaço adaptado no qual os alunos possam buscar o conhecimento, sem quaisquer limitações de seu direito em participar ativamente das atividades. Tendo em vista que a educação inclusiva parte do pressuposto que a escola faz parte da vida de todos, e para atender as necessidades de cada indivíduo, são necessárias transformações políticas, estruturais, ideológicas e sociais. 


\section{REFERÊNCIAS}

AMIRALIAN, M. L. T.; PINTO, E. B.; GHIRARDI, M. I. G.; LICHTIG, I.; MASINI, E. F. S.; PASQUALIN, L. Conceituando deficiência. Revista de Saúde Pública, São Paulo, v. 34, n. 1 p. 97-103, fev. 2000

ARAUJO, A. D.; MAIA, M. A cidade, o dever constitucional de inclusão social e a acessibilidade. Revista de Direito da Cidade, Rio de Janeiro, v. 8, n. 1, p. 225-44, 2016.

BENEDITO, A.; MENEZES, D. F. N. Políticas públicas de inclusão social: o papel das empresas. Revista Ética e Filosofia Política, Rio de Janeiro, v. 1, n. 16, p. 1-20, jun. 2013.

BIGARELLA, N.; LEWANDOWSKI, A. G.; CARVALHO, J. A. B. A Educação Especial como um dos direitos humanos: contextualização fática das políticas educacionais. Multitemas, Campo Grande, MS, v. 22, n. 51, p. 289-313, jan./jun. 2017.

BRASIL. Supremo Tribunal Federal. Ação Direta de Inconstitucionalidade n. 5357. Relator Min. Edson Fachin. Brasília, DF, Tribunal Pleno, julgado em 09 jun. 2016

. Lei n. 13.146, de 6 de julho de 2015. Institui a Lei Brasileira de Inclusão da Pessoa com Deficiência (Estatuto da Pessoa com Deficiência). Disponível em: <http://www.planalto.gov.br/ccivil_03/_ato2015-2018/2015/lei/l13146.htm>. Acesso em: 27 abr. 2018.

. Cartilha do Censo 2010 - Pessoas com Deficiência / Luiza Maria Borges Oliveira / Secretaria de Direitos Humanos da Presidência da República (SDH/PR) / Secretaria Nacional de Promoção dos Direitos da Pessoa com Deficiência (SNPD) / Coordenação-Geral do Sistema de Informações sobre a Pessoa com Deficiência; Brasília: SDH-PR/SNPD, 2012.

. Avanço das políticas públicas para as pessoas com deficiência. Uma análise a partir das conferências internacionais. 1. ed. Brasília: [s.n.], 2012

. Convenção sobre os Direitos das Pessoas com Deficiência (2007). Convenção sobre os Direitos das Pessoas com Deficiência: Protocolo Facultativo à Convenção sobre os Direitos das Pessoas com Deficiência: decreto legislativo n. 186, de 9 de julho de 2008: decreto n. 6.949, de 25 de agosto de 2009. 4. ed. rev. e atual. Brasília: Secretaria de Direitos Humanos, Secretaria Nacional de Promoção dos Direitos da Pessoa com Deficiência, 2011.

Ministério da Educação. Política Nacional de Educação Especial na perspectiva da educação inclusiva. 2008. Disponível em: <http://portal.mec. gov.br/index.php?option=com_docman\&view=download\&alias=16690politica-nacional-de-educacao-especial-na-perspectiva-da-educacao-inclusiva05122014\&Itemid=30192>. Acesso em: 27 abr. 2018. 
. Decreto n. 3.956, de 8 de outubro de 2001a. Promulga a Convenção Interamericana para Eliminação de Todas as Formas de Discriminação contra as Pessoas Portadoras de Deficiência. Disponível em: <http://www.planalto.gov.br/ ccivil_03/decreto/2001/d3956.htm>.

. Ministério da Educação. Diretrizes nacionais para a educação especial na educação básica. Brasília: Secretaria de Educação Especial, 2001b. 79p.

. Lei n. 9.394, de dezembro de 1996. Estabelece as diretrizes da educação nacional. Disponível em: <http://www.planalto.gov.br/ccivil_03/leis/L9394.htm>. Acesso em: 27 abr. 2018.

. Constituição da república Federativa do Brasil de 1988. Disponível em: <http://www.planalto.gov.br/ccivil_03/Constituicao/Constituicao.htm>. Acesso em: 27 abr. 2018.

BRUMER, A.; PAVEI, K.; MOCELIN, D. G. Saindo da "escuridão": perspectivas da inclusão social, econômica, cultural e política dos portadores de deficiência visual em Porto Alegre. Sociologias, Porto Alegre, ano 6, n. 11, p. 300-27, jan./jun. 2004. CARVALHO, L. C.; SALERNO, M. B.; ARAUJO, P. F. A educação especial nas leis de diretrizes e bases da educação brasileira: uma transformação em direção à inclusão educacional. Horizontes - Revista de Educação, Dourados, MS, v. 3, n. 6, p. 34-48, jul./dez. 2015.

CARVALHO, R. Educação inclusiva: com os pingos nos "is". 11. ed. Porto Alegre: Mediação, 2016.

FRANÇA, I. S. X.; PAGLIUCA, L. M. F. Acessibilidade das pessoas com deficiência ao SUS: Fragmentos históricos e desafios atuais. Revista RENE, Fortaleza, v. 9, n. 2, p. 129-37, abr./jun. 2008.

FRANÇA, I. S. X.; PAGLIUCA, L. M. F.; BAPTISTA, R. S. Política de inclusão do portador de deficiência: possibilidades e limites. Acta Paulista de Enfermagem, São Paulo, v. 21, n. 1, p. 112-6, jan./mar. 2008.

HÖFLING, E. M. Estado e políticas (públicas) sociais. Cadernos Cedes, Campinas, SP, ano XXI, n. 55, p. 30-41, nov. 2001.

NERI, M. et al. Retratos da deficiência no Brasil. Rio de Janeiro: FGV/IBRE, CPS, 2003. RODRIGUES, E. O.; DUTRA, A. D.; STORTO, L. J. Inclusão escolar na educação de jovens e adultos. Revista Eletrônica de Educação, São Carlos, v. 11, n. 1, p. 243-59, jan./maio 2017.

ROSSETTO, E.; ADAMI, A. S.; KREMER, J.; PAGANI, N.; SILVA, M. T. N. Aspectos históricos da pessoa com deficiência. Educere et Educare, Cascavel, PR, v. 1, n. 1, p. 103-8, jan./jun. 2006. 
SCHEWINSKY, S. R. A barbárie do preconceito contra o deficiente- todos somos vítimas. Revista Acta Fisiátrica, São Paulo, v. 11, n. 1, p. 7-11, 2004.

SENA, M. C.; SILVA, G.; MARQUES, H. R.; BASTOS, P. R. H. O. Responsabilidade civil por erro médico. Multitemas, Campo Grande, MS, v. 22, n. 52, p. 35-52, jul./dez. 2017. SOUSA, A. E. M.; LOPES, B. B.; MAIA, M. B. P. Educação inclusiva na educação profissional: um estudo de caso à luz da experiência em uma Escola Estadual de Educação Profissional no município de Santa Quitéria-CE. Revista Brasileira da Educação Profissional e Tecnológica, Natal, RN, v. 1, n. 7, p. 107-14, 2014.

TORTORA, T.; DERRICKSON, B. Corpo humano: fundamentos de anatomia e fisiologia. 8. ed. Porto Alegre: Artmed, 2012. 239p.

VYGOTSKY, L. S. Pensamento e linguagem. Lisboa: Antídoto, 1979. 
